\title{
INVESTIGATION OF THERMO-FLUID BEHAVIOUR OF NANOFLUID THROUGH A CORRUGATED TUBE
}

\author{
Mohammad Monjurul Ehsan ${ }^{1}$, Shafi Noor ${ }^{2}$ \\ ${ }^{1,2}$ Department of Mechanical and Chemical Engineering (MCE), Islamic University of Technology (IUT), Gazipur, \\ Bangladesh, \\ 'ehsan@iut-dhaka.edu, ${ }^{2}$ shafi@iut-dhaka.edu
}

\begin{abstract}
Heat transfer enhancement using nanofluid through a plain tube or corrugated plate has been investigated by many researchers during the last few years. Despite of this improvement, it has not been studied with the justification of using aluminum oxide nanofluid in a corrugated tube in terms of the increased power needed for the flow due to the change in thermophysical properties of nanofluid compared to that of the basefluid. In the present study, the use of nanofluid in a V-shaped corrugated tube for a turbulent flow in order to enhance the heat transfer rate and corresponding pumping power required has been analyzed for Reynolds number- 4000 to 20000. To accomplish heat transfer enhancement, nanofluid requires increased pumping power and the justification of using nanofluid in terms of pumping power is not studied in most of the research articles. So the scope of our present work is to study turbulent forced convection heat transfer and pumping power through a V-shaped corrugated tube subjected to uniform heat flux using Al2O3-water nanofluid. The study is performed for a range of volume fraction 1\% to 5\% and the diameter of nanoparticle is considered as $50 \mathrm{~nm}$. With an increase of Reynolds number and volume fraction nanofluid provides substantial improvement of heat transfer and reduction of pumping power for optimum volume fraction. For a constant heat transfer coefficient of $10000 \mathrm{~W} / \mathrm{m} 2 \mathrm{~K}$, the minimum pumping power is obtained for $3 \%$ volume fraction of nanofluid flowing through corrugated tube which is $40 \%$ lower than that of water.
\end{abstract}

Keywords: Nanofluid, Pumping Power, Corrugation, Heat Transfer, Turbulent Flow.

\section{INTRODUCTION}

Numerous researches have been performed in the last few decades to discover a more suitable heat transfer fluid to design compact heat exchangers with excellent thermal performance for industrial and engineering applications. Nanotechnology is an innovative technique to improve the heat transfer characteristics of working fluid by the uniform and stable suspension of solid nanoparticles in conventional base fluid. By the addition of nanoparticles with preferred volume concentration, the thermo-physical properties of working fluid are substantially improved which potentially lead to enhance the thermal and hydrodynamic behaviour of nanofluid [1-5]. The implementation of corrugation in the geometry and suspension of nanoparticles in base fluid are becoming an innovative and inexpensive ways for increasing the heat transfer rate in many aspects of heat transfer applications.

Maiga et al. [6] analyzed the heat transfer behavior of $\gamma$ $\mathrm{Al}_{2} \mathrm{O}_{3}$-water and $\gamma-\mathrm{Al}_{2} \mathrm{O}_{3}$-ethylene glycol nanofluids through a circular tube with constant heat flux for both laminar and turbulent flow condition. Addition of nanoparticles had an increased effect on the heat transfer rate, whereas the wall shear stress became decreased with volume fraction. The authors also investigated the laminar forced convection heat transfer improvement through a uniformly heated tube and parallel, coaxial and heated disk where $\gamma-\mathrm{Al}_{2} \mathrm{O}_{3}$-ethylene glycol nanofluid showed better heat transfer rate compared to $\gamma$ - $\mathrm{Al}_{2} \mathrm{O}_{3}$-water [7]. Behzadmehr et al. [8] performed numerical investigation of $\mathrm{Cu}$-water nanofluid with $1 \%$ volume fraction through a circular tube to observe the improvement of heat transfer rate under turbulent flow condition with single phase model and results were compared with mixture model. Abu Nada [9] worked with $\mathrm{Cu}, \mathrm{Ag}$ and $\mathrm{TiO}_{2}$ nanoparticles dispersed in water over a backward facing step and showed increase inNusselt number under forced laminar convection. Bianco et al. [10] proposed a numerical model to observe the heat transfer behavior of $\mathrm{Al}_{2} \mathrm{O}_{3}$-water nanofluid through a circular tube employing both single and two phase model. Devdatta et al. [11] conducted experiment with a circular tube of a heat exchanger with $\mathrm{Al}_{2} \mathrm{O}_{3}, \mathrm{TiO}_{2}$ and $\mathrm{CuO}$ nanoparticles suspended in 60:40 ethylene glycol-water mixture up to $6 \%$ volume fraction and concluded that implementation of nanoparticles had reduced the volumetric and mass flow rate of working fluid which finally improved the pumping power savings. Izadi et al. [12] numerically studied hydrodynamic and thermal behaviour of laminar forced convection of $\mathrm{Al}_{2} \mathrm{O}_{3}$-water nanofluid through the annulus. Convective heat transfer coefficient, friction coefficient, temperature and velocity profiles are examined and it was reported that at higher Reynolds number, the improvement of momentum energy was dependent on the decrement of nanoparticles volume fraction. Heat transfer augmentation was reported by Santra et al. [13] by $\mathrm{Cu}$-water nanofluid as a cooling medium through two isothermally heated parallel plates for a range of Reynolds number 5 to 1500 and volume concentration up to 5\%.Weerapun and Somchai [14] experimented with double-tube counter flow heat exchanger 
to study the pressure drop and heat transfer with $\mathrm{TiO}_{2}$-water nanofluid for a range of Reynolds number 4,000-18,000. The maximum convective heat transfer coefficient was $11 \%$ higher compared to base fluid and heat transfer rate was increased with an increase of Reynolds number with a little penalty in pressure drop. Yurong et al. [15] performed experiment with $\mathrm{TiO}_{2}$-water nanofluid through a straight tube to investigate the effect of size and volume fraction of nanoparticles and Reynolds number on the enhancement of average Nusselt number. Nasiri et al. [16] reported experimental results on thermal performance of $\mathrm{Al}_{2} \mathrm{O}_{3}$-water and $\mathrm{TiO}_{2}$-water nanofluid through an annular duct with constant wall temperature under turbulent flow condition. Study was performed for a range of Reynolds number 4,000-12,000, Peclet number- 25,000 to 60,000 and volume fraction up to $1.5 \%$.SakrFadl [17] investigated the thermal performance and pumping power using three different corrugated channel (Trapezoidal, Triangle and semicircular) and trapezoidal and triangle ribs channel showed better performance due to sharp edges.

Numerous studies were performed by researchers in recent years with corrugation applied in the wall boundary to obtain better hydrodynamic and thermal performance [1822]. Heidary and Kermani [23] investigated the heat transfer improvement using $\mathrm{Cu}$-water nanofluid through a sinusoidal wavy channel under laminar flow condition. Nusselt number and skin friction coefficient were studied for a range of Reynolds number from 5 to 1500 , and volume fraction up to $20 \%$. Ahmed et al. [24] carried out numerical investigation of laminar heat transfer and pressure drop characteristics of $\mathrm{Cu}$-water nanofluid through an isothermally heated triangular shaped corrugated channel and observed the enhancement of average Nusselt number with an increase of Reynolds number and volume fraction. Yousoff et al. [25] performed the effects of volume fraction, wave amplitude and Reynolds number on the improvement of friction coefficient and Nusselt number through a uniformly heated sinusoidal wavy channel using nanofluid. Adnan et al. [26] performed experiment to observe the significant improvement of heat transfer using $\mathrm{TiO}_{2}$-water nanofluid in a car radiator for Reynolds number 4,000-16,000 and volume fraction $1 \%$ to $2.5 \%$. Three different geometries (Circular, flat and elliptical tube) were employed to study the friction factor and heat transfer characteristics and flat tube showed highest convective heat transfer coefficient. Enhancement of Nusselt number with an increase of Reynolds number, particle volume fraction and wave amplitude were also studied numerically through a trapezoidal-corrugated channel for laminar forced convection [27]. Ranjbar et al. [28] investigated the turbulent convective heat transfer augmentation in a wavy channel under constant wall heat flux using $\mathrm{Al}_{2} \mathrm{O}_{3}$-water nanofluid and two phase model was considered. Ashkan and Muhammad [29] studied the thermal and hydraulic behaviour of flow in a horizontal periodic rib-grooved channel like triangular, square and arc shaped for turbulent forced convection utilizing $\mathrm{Al}_{2} \mathrm{O}_{3}, \mathrm{SiO}_{2}, \mathrm{CuO}, \mathrm{ZnO}$ nanoparticles dispersed in water and reported a considerable amount of heat transfer enhancement with negligible increase in friction factor.
From the literature study it may be mentioned that most of the works focused on the heat transfer enhancement utilizing nanofluid in a corrugated channel. The study is performed for a wide range of Reynolds number 4,000-20,000 for particles volume fraction $1 \%$ to $5 \%$. The optimum volume fraction for which nanofluid provides lesser amount of pumping power compared to base fluid is determined along with the improvement of heat transfer coefficients with an increase of Reynolds number and volume fraction.

\section{NOMENCLATURE}

Ac Cross-sectional area of tube

Aw surface area of tube

$\mathrm{Cp} \quad$ Specific heat at constant pressure

D Diameter of the tube

hc Average heat transfer coefficient

$\mathrm{k}$ Thermal conductivity

$\Delta \mathrm{P} \quad$ Pressure difference

Q Heat transfer

q Heat flux

$\mathrm{T}$ Temperature

U Velocity of flow at inlet

W Pumping power per unit length

Greek symbols

$\phi \quad$ Volume fraction

$\mu \quad$ Dynamic viscosity

$v \quad$ Kinematic viscosity

$\rho \quad$ Mass density

Subscripts

av Average value

i Value at inlet

o Value at outlet

nf Nanofluid

bf Basefluid

p Nanoparticle

w Value at wall

max Maximum value

min Minimum value

Dimensionless parameter

$\mathrm{Nu} \quad$ Nusselt number

Re Reynolds number

Pr Prandl number

\section{GOVERNING EQUATION}

The two dimensional transport equations for continuity, momentum and energy equation for forced convection under turbulent flow and steady state condition are expressed as follows

Continuity equation:

$\frac{\partial}{\partial x_{i}}\left(\rho u_{i}\right)=0$

Momentum equation:

$$
\frac{\partial\left(\rho u_{i} u_{j}\right)}{\partial x_{j}}=-\frac{\partial p}{\partial x_{i}}+\frac{\partial}{\partial x_{j}}\left[\mu\left(\frac{\partial u_{i}}{\partial x_{j}}+\frac{\partial u_{j}}{\partial x_{i}}\right)\right]+\frac{\partial}{\partial x_{j}}\left(-\rho \overline{u_{i}^{\prime} u_{j}^{\prime}}\right)
$$


Energy equation:

$$
\frac{\partial}{\partial x_{i}}\left(-\rho u_{i} T\right)=\frac{\partial}{\partial x_{j}}\left(\left(\Gamma+\Gamma_{t}\right) \frac{\partial T}{\partial x_{j}}\right)
$$

Here $\Gamma$ is molecular thermal diffusivity and $\Gamma_{t}$ is turbulent thermal diffusivity which can be expressed as:

$\Gamma=\frac{\mu}{P r^{\prime}}$

$\Gamma_{t}=\frac{\mu_{t}}{P r_{t}^{\prime}}$

The Reynolds number for the flow of nanofluid is expressed as $R e=\frac{\rho_{n f} U_{a v} D}{\mu_{n f}}$

The rate of heat transfer $\mathrm{Q}_{\mathrm{nf}}$ to tube wall is assumed to be totally dissipated to nanofluid flowing through a corrugated tube, raising its temperature from inlet fluid bulk temperature $T_{b i}$ to exit fluid bulk temperature $T_{\text {bo }}$. Thus,

$$
Q_{n f}=\dot{m}_{n f} C_{P_{n f}}\left(T_{b o}-T_{b i}\right)_{n f}
$$

Where $\dot{m}_{n f}$ is the mass flow rate of nanofluid, $\mathrm{C}_{\mathrm{Pnf}}$ is the specific heat of nanofluid at constant pressure. The definition of bulk temperature $T_{b}$ is given by

$$
T_{b}=\frac{\int_{0}^{A_{C}} u T d A_{C}}{\int_{0}^{A_{C}} u d A_{C}}
$$

The average heat transfer coefficient, $h_{c}$ is given by

$$
h_{c}=\frac{Q_{n f}}{A_{W}\left(\Delta T_{m}\right)}
$$

Where $A_{w}$ is the surface area of circular tube and $\Delta T_{m}$ is the difference between the wall temperature and the average bulk temperature of the fluid. The average wall temperature $\mathrm{T}_{\mathrm{w}}$ is computed by

$$
T_{w}=\frac{1}{\sigma} \int_{0}^{\sigma} T_{w, x} d x
$$

So the expression of average Nusselt number is defined as follows

$$
N u=\frac{h_{c} D}{k_{n f}}
$$

The pumping power per unit length in turbulent flow is given by

$$
W=\frac{\frac{\pi}{4} D_{h}{ }^{2} U_{a v} \Delta P}{L}
$$

Where $\Delta \mathrm{P}$ is the pressure difference

$$
\Delta P=\frac{f L \rho U_{a v}^{2}}{2 D}
$$

\section{THERMOPHYSICAL PROPERTIES OF NANOFLUID}

The density and specific heat of $\mathrm{Al}_{2} \mathrm{O}_{3}$-water nanofluid are given below [30]

Density, $\rho_{n f}=\rho_{p} \phi+\rho_{b f}(1-\phi)$

Specific heat, $C_{n f}=(1-\phi) C_{b f}+\phi C_{p}$

The thermal conductivity of the nanofluid is calculated using the correlation proposed by Koo and Kleinstreuer [31]. To calculate the effective thermal conductivity, the diameter of the solid nanoparticles, volume fraction and temperature of the nanofluid, properties of the base fluid and nanoparticles and the Brownian motion of the solid particles within the base fluid have been considered.

Thermal conductivity,

$$
\begin{gathered}
k_{n f}=\frac{k_{p}+2 k_{b f}+2\left(k_{p}-k_{b f}\right) \phi}{k_{p}+2 k_{b f}-\left(k_{p}-k_{b f}\right) \phi} k_{b f}+5 \\
\times 10^{5} \beta \phi \rho_{p} C_{p} \sqrt{\frac{K_{B} T}{\rho_{p} D}} f(T, \phi)
\end{gathered}
$$

Where, $f(T, \phi)=(-6.04 \phi+0.4705) T+(1722.3 \phi-134.63)$

The dynamic viscosity of nanofluid is calculated by using the following empirical correlation developed by Corcione [32] with a $1.84 \%$ of standard deviation.

$$
\frac{\mu_{n f}}{\mu_{b f}}=\frac{1}{1-34.87\left(\frac{d_{p}}{d_{b f}}\right)^{-0.3} \phi^{1.03}}
$$

Where $d_{b f}$ is the equivalent diameter of the base fluid molecule, and is given by

$$
d_{b f}=\left[\frac{6 M}{N \pi \rho_{f o}}\right]^{1 / 3}
$$

Where $\mathrm{M}$ is the molecular weight of the base fluid, $\mathrm{N}$ is the Avogadro number, and $\rho_{\mathrm{fo}}$ is the mass density of the base fluid calculated at temperature $T_{o}=293 \mathrm{~K}$. In the present study the nanoparticles are assumed to have a diameter of 50 $\mathrm{nm}$ in order to calculate the effective thermal conductivity and viscosity. 


\section{PHYSICAL MODEL AND BOUNDARY} CONDITION

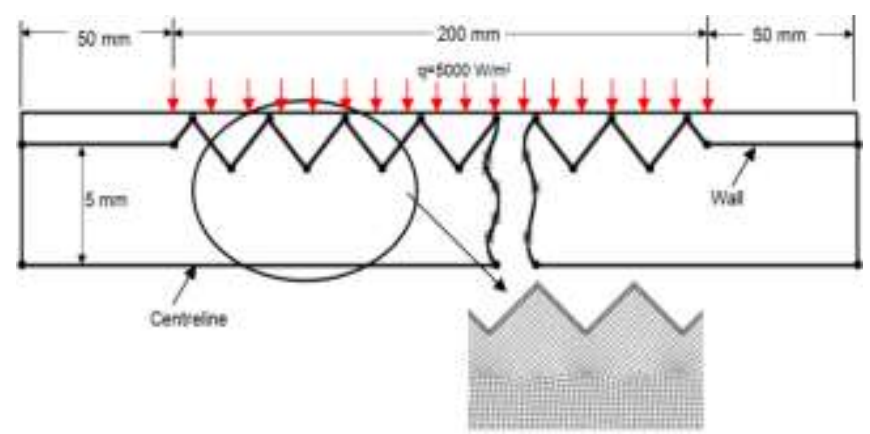

Fig-1: A 2D model of the circular corrugated tube and the corresponding mesh showing inflation at the wall (not to scale)

A numerical investigation of turbulent flow through a circular, plain and a V-shaped corrugated tube with constant heat flux of $5000 \mathrm{~W} / \mathrm{m}^{2}$ applied on its surface have been considered in this study. The diameter of both of the tubes is taken as $10 \mathrm{~mm}$. In case of the circular tube, the calculation has been done at a fully developed section and $1 \mathrm{~m}$ long tube is taken where the heat transfer coefficient was measured at a distance of $800 \mathrm{~mm}$ from the inlet. The pressure has been measured at two sections- $800 \mathrm{~mm}$ and $900 \mathrm{~mm}$ from the inlet respectively to measure the pressure drop. A 2D simulation with axisymmetric model has been considered. For both tubes, fluid is allowed to flow with a uniform velocity and uniform temperature of $300 \mathrm{~K}$ at the inlet of the tube with an assumption of no slip condition. In case of the corrugated tube, which is shown in figure 1 , the pressure and bulk temperature of the fluid are measured at the beginning and end of the corrugated section. The corrugation has an amplitude of $1 \mathrm{~mm}$ and wavelength of 4 mm. Realizable $\mathrm{k}-\varepsilon$ turbulent model is chosen with enhanced wall treatment for the single phase analysis. Turbulent intensity is taken as $5 \%$ at the inlet and at the outlet boundary "pressure outlet" is considered. Heat transfer parameters like convective heat transfer coefficient and average Nusselt number and fluid dynamic parameters like pressure drop, friction factor and pumping power are calculated. With an increase of Reynolds number and particle volume fraction heat transfer characteristics, fluid flow behaviour and pumping power are investigated. By the addition of nanoparticles with a low volume concentration in base fluid, the enhancement of heat transfer, the increase of frictional losses, and the reduction of pumping power in comparison with water are studied under the prescribed flow condition.

\section{GRID INDEPENDENCE TEST AND CODE VALIDATION}

To study the heat transfer behaviour and pumping power requirement numerically for the flow of fluid through the circular plain and corrugated tube, commercial computational fluid dynamics software - ANSYS Fluent [34] has been employed in the present work. Water is considered as the working substance and Nusselt number measured by numerical method at the fully developed region is compared with the correlation proposed by Notter and Sleicher [33]. From figure 2 it is obvious that the numerical results of the present study are in good agreement with the Nusselt number obtained using Notter and Sleicher correlation.The correlation developed by Notter and Sleicher is as follows:

$$
\mathrm{Nu}=5+0.016 \operatorname{Re}^{\mathrm{a}} \operatorname{Pr}^{\mathrm{b}}
$$

Where, $a=0.88-\frac{0.24}{4+P r} \quad$ and $\quad \mathrm{b}=0.33+0.5 \mathrm{e}^{(-0.6 \mathrm{Pr})}$

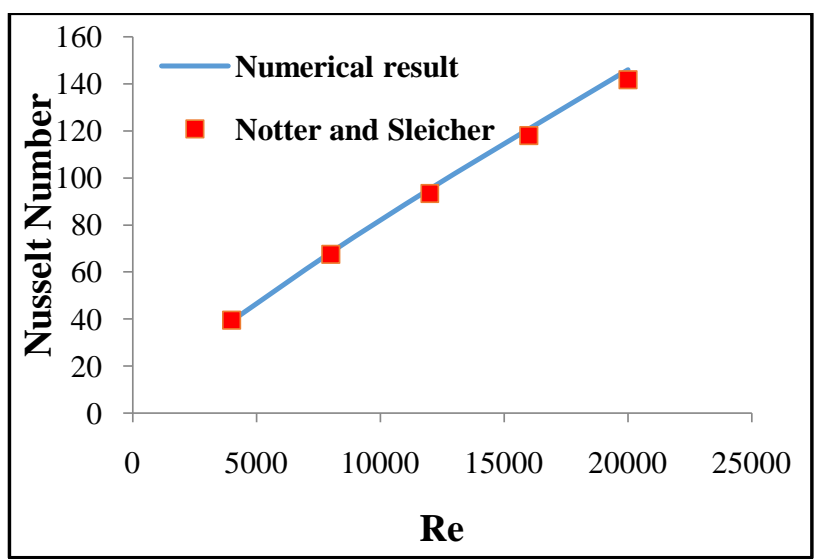

Fig-2: Comparison of Nusselt number between the numerical results from present work and Notter and Sleicher correlation [33].

Taking water as the working substance, for the circular plain tube, an optimum grid size of $600 \times 40$ has been used with a bias factor of 10 towards the inlet and outlet as well as the wall of the tube. Beyond this size of the grid, there is not any significant change in the friction factor values. For the circular corrugated tube, friction factor has been calculated using the pressure drop measured from $\mathrm{x}=50 \mathrm{~mm}$ to $\mathrm{x}=250$ $\mathrm{mm}$ for the grid sizes $-9600,14200,22300,31200,46000$, 61600. It has been observed that beyond a grid size of 46000 , there is very negligible change in the friction factor value. Therefore for the present study, a grid size of 46000 has been taken for the fluid domain.

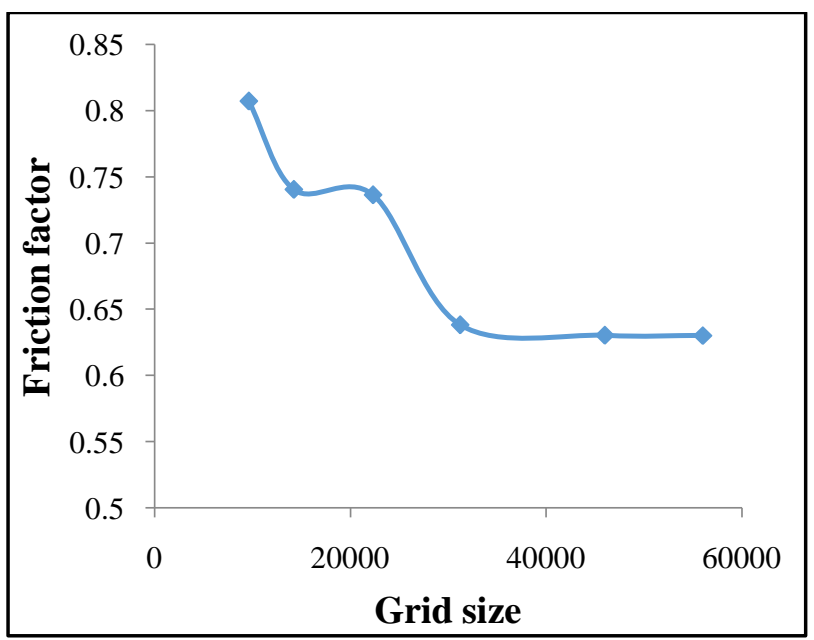

Fig-3: Friction factor at $\mathrm{Re}=12000$ for different grid sizes of the fluid domain. 


\section{RESULTS AND DISCUSSION}

\subsection{Effect of Volume Fraction of Nanofluid}

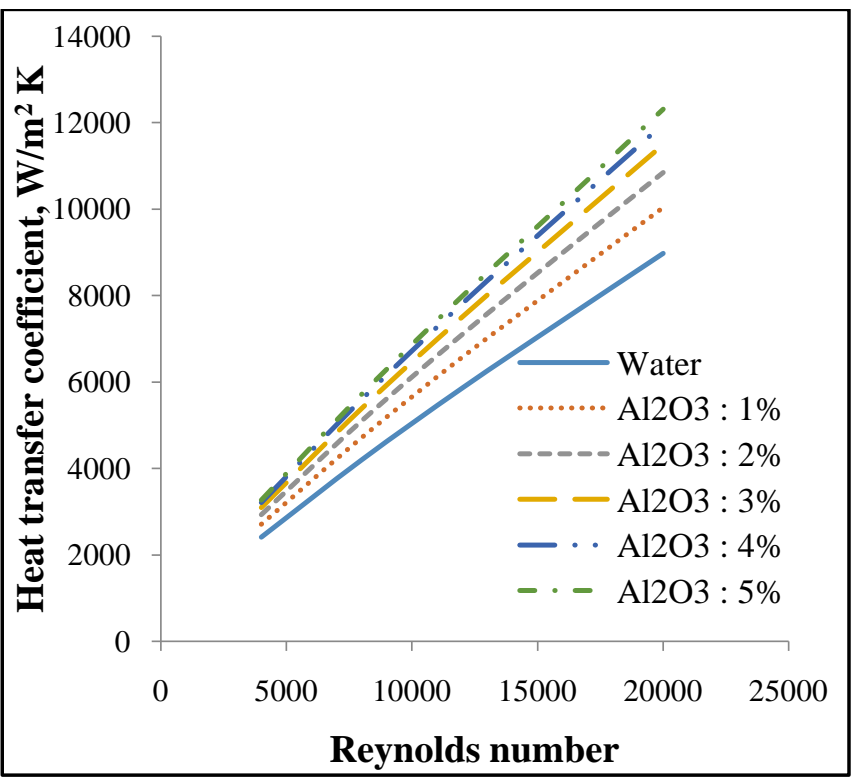

Fig-4: Heat transfer enhancement using nanofluid through circular plain tube.

From figure 4 it is seen that the addition of nanoparticle in the base fluid water has an effect of increasing the heat transfer rate which becomes higher at a greater volume fraction of the nanofluid. At a Reynolds number of 12000 , the heat transfer coefficient obtained using $\mathrm{Al}_{2} \mathrm{O}_{3}$-water nanofluid of $5 \%$ volume fraction is $36.3 \%$ higher than that obtained from water. This trend is obtained in case of corrugated tube also which is shown in figure 5. However for corrugated tube, the enhancement effect using nanofluid is higher compared to water, e.g. the heat transfer rate with nanofluid of $5 \%$ volume fraction flowing through the tube is $39.8 \%$ higher than that with water.

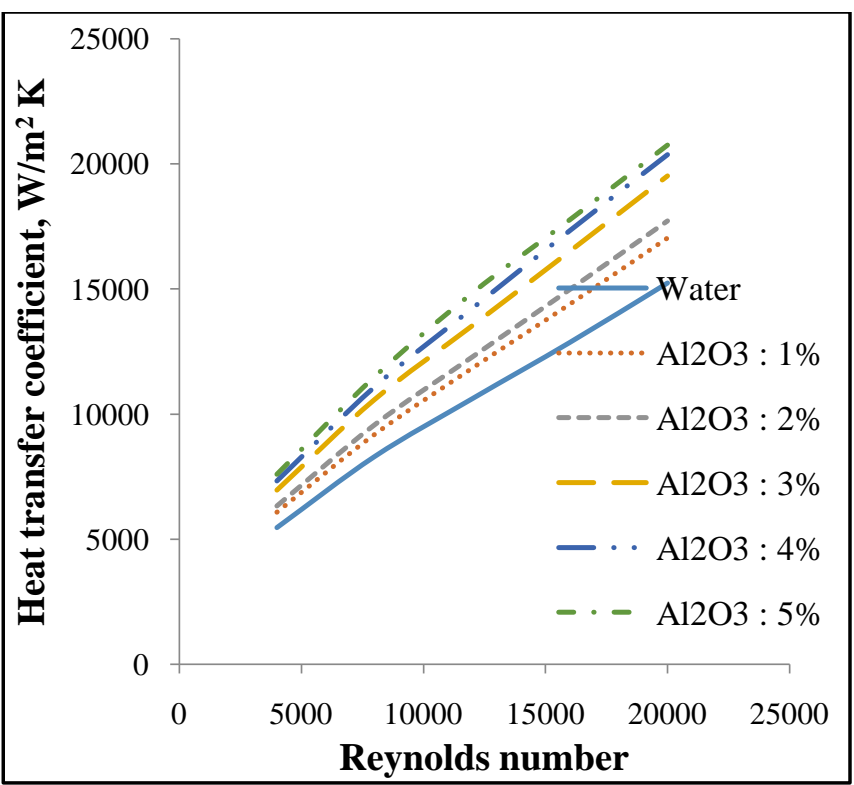

Fig-5: Heat transfer enhancement using nanofluid through corrugated tube

\subsection{Effect of Corrugation}

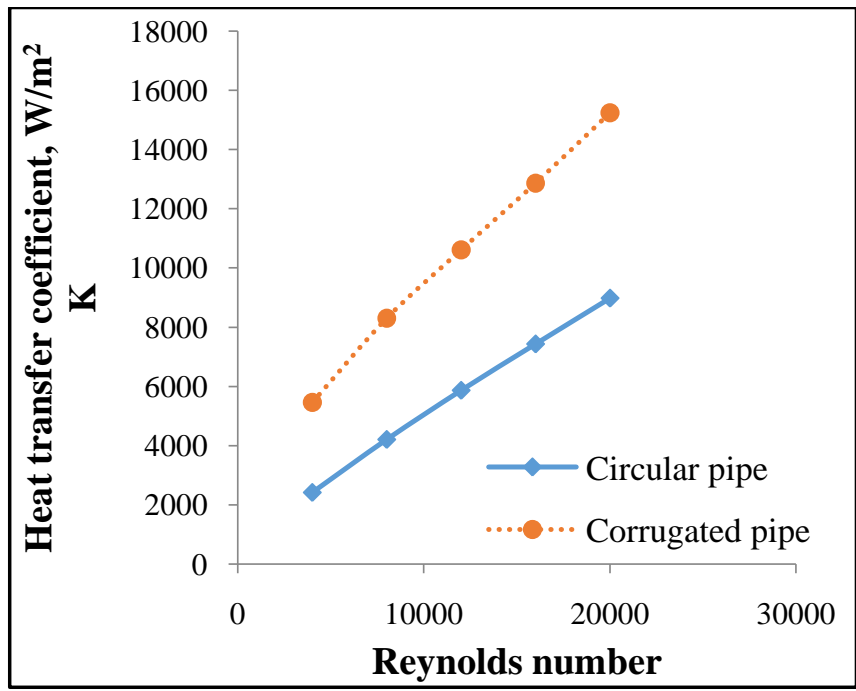

Fig-6: Heat transfer enhancement using corrugated tube and water as the working substance

The use of corrugated tube contributes in the enhancement of the heat transfer coefficient comparing to the circular plain tube. From figure 6, at a Reynolds number of 12000 , the heat transfer coefficient for circular tube is $5862 \mathrm{~W} / \mathrm{m}^{2}$ $\mathrm{K}$ and it is $10613 \mathrm{~W} / \mathrm{m}^{2} \mathrm{~K}$ for corrugated tube. This enhancement of heat transfer using corrugation in the fluid domain shows an increasing trend with the increase in the Reynolds number.

From figure 7 , the required pumping power for corrugated tube is higher than that of plain tube. With the increase in the Reynolds number, the pumping power requirement for corrugated tube increases. In addition to this, the rate at which required pumping power increases is much higher for corrugated tube than that of plain circular tube. Similar trend is seen for the nanofluid of various volume fractions.

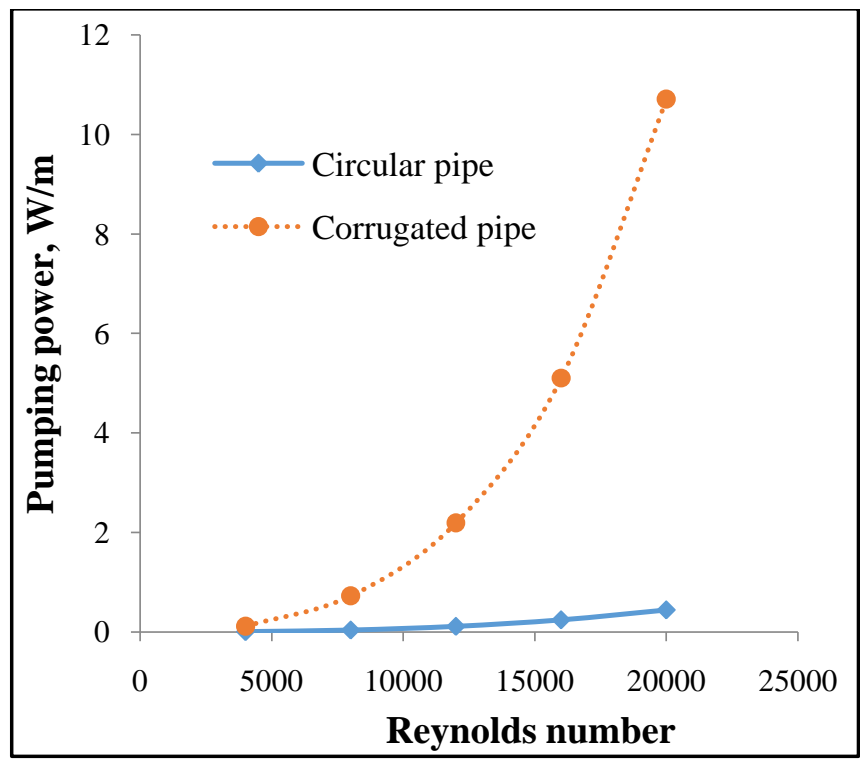

Fig-7: Comparison between the pumping powers obtained using plain and corrugated tube for water as the flowing fluid. 
Figure 8 shows a comparison of the required pumping power per unit length for both circular and corrugated tube with the change in the heat transfer coefficient. The requirement of pumping power is always higher for corrugated tube than the plain tube in case of $1 \% \quad \mathrm{Al}_{2} \mathrm{O}_{3}$ water nanofluid. At $\mathrm{h}=8000 \mathrm{~W} / \mathrm{m}^{2} \mathrm{~K}$, the pumping power for corrugated tube is $0.495 \mathrm{~W} / \mathrm{m}$ and that for plain tube is 0.26 $\mathrm{W} / \mathrm{m}$. The same results are obtained for water and nanofluid of other volume fractions as well.

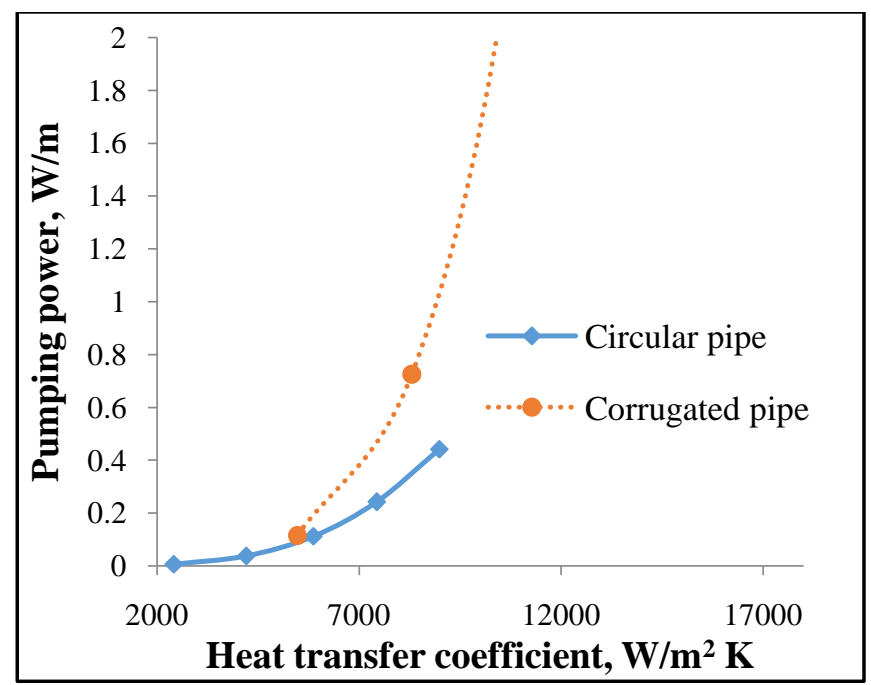

Fig-8: Comparison between the pumping power for corrugated tube and plain tube.

\subsection{Effect of Nanofluid}

As the volume fraction of the nanofluid increases, the requirement of pumping power reduces for the same heat transfer rate. This pumping power is the lowest at a volume fraction of $2 \%$ beyond which the pumping power increases again. And at a volume fraction of $5 \%$, the pumping power requirement is more than that of water when same heat transfer rate is required [see figure 9].

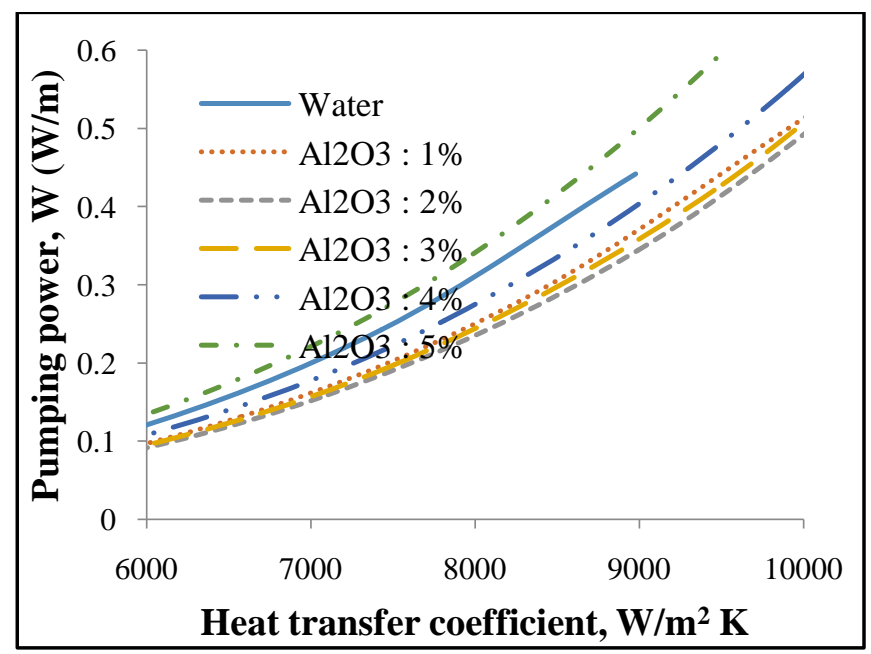

Fig-9: Comparison of pumping power for nanofluid with that for water at the same heat transfer coefficient for circular plain tube (zoomed from $\mathrm{h}=6000 \mathrm{~W} / \mathrm{m}^{2} \mathrm{~K}$ to $\left.\mathrm{h}=10000 \mathrm{~W} / \mathrm{m}^{2} \mathrm{~K}\right)$.
The use of nanofluid results in the reduction in the pumping power requirement compared to water. In figure 10 , it is seen that with the increase in the volume fraction of the nanofluid, the pumping power requirement decreases compared to water. At a volume fraction of $3 \%$, pumping power is the lowest and at a higher volume fraction it increases again. Unlike plain tube, here at a volume fraction of $5 \%$, the pumping power requirement is still lower than that of water. However, from the increasing trend of the pumping power requirement beyond the volume fraction of $3 \%$, it may be inferred that the pumping power line of nanofluid will cross that of water at a higher volume fraction of nanofluid.

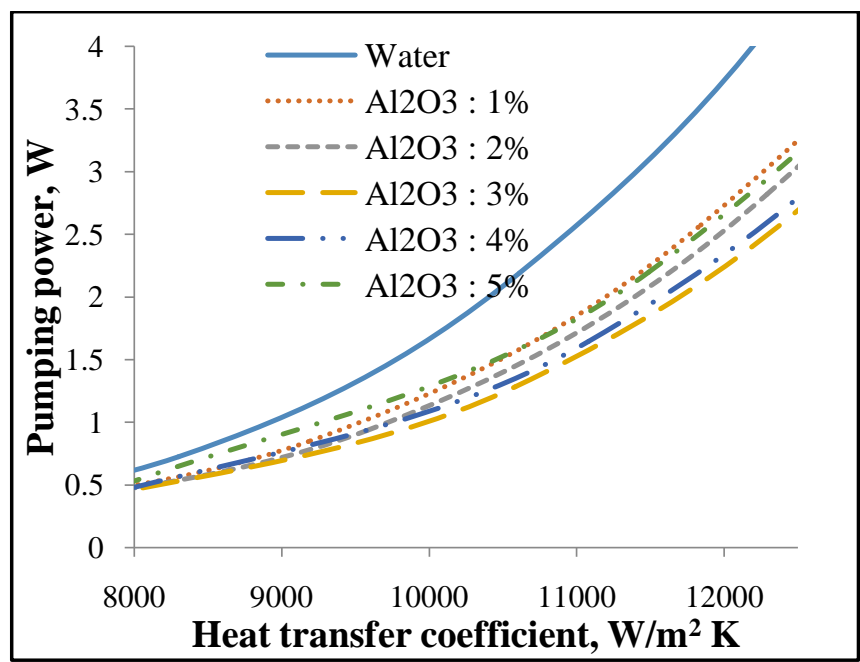

Fig-10: Comparison of pumping power for nanofluid and water for corrugated tube (zoomed from $\mathrm{h}=8000 \mathrm{~W} / \mathrm{m}^{2} \mathrm{~K}$ to $\left.\mathrm{h}=12500 \mathrm{~W} / \mathrm{m}^{2} \mathrm{~K}\right)$.

Water through circular tube requires much less pumping power whereas corrugation in the geometry involves with higher pumping power requirement shown in figure 11 . However this pumping power can be reduced by using nanofluid. For example at $\mathrm{h}=8000 \mathrm{~W} / \mathrm{m}^{2} \mathrm{~K}$, using nanofluid of $3 \%$ volume fraction flowing through corrugated tube results in $29.5 \%$ reduction in the pumping power. When heat transfer requirement is lower, i.e. $7000 \mathrm{~W} / \mathrm{m}^{2} \mathrm{~K}$, the pumping power requirement becomes equal to that of circular tube. On the other hand, when the pumping power is constant, the heat transfer coefficient is the highest for the case of $\mathrm{Al}_{2} \mathrm{O}_{3}$-water nanofluid of volume fraction of $2 \%$ flowing through circular tube. The following table draws a comparison among the heat transfer coefficients for different working conditions.

Table 1: Comparison among heat trasnfer

\begin{tabular}{|l|l|l|}
\hline \multicolumn{1}{|c|}{$\begin{array}{c}\text { Working } \\
\text { substance }\end{array}$} & \multicolumn{1}{|c|}{ Fluid domain } & $\begin{array}{c}\text { Heat transfer } \\
\text { coefficient } \\
\left(\mathbf{W} / \mathbf{m}^{2} \mathbf{K}\right)\end{array}$ \\
\hline $\begin{array}{l}\mathrm{Al}_{2} \mathrm{O}_{3}-\mathrm{H}_{2} \mathrm{O} \text { of } \\
\phi=2 \%\end{array}$ & Circular tube & 9400 \\
\hline Water & Circular tube & 8700 \\
\hline $\begin{array}{l}\mathrm{Al}_{2} \mathrm{O}_{3}-\mathrm{H}_{2} \mathrm{O} \text { of } \\
\phi=3 \%\end{array}$ & Corrugated tube & 7750 \\
\hline Water & Corrugated tube & 7100 \\
\hline
\end{tabular}




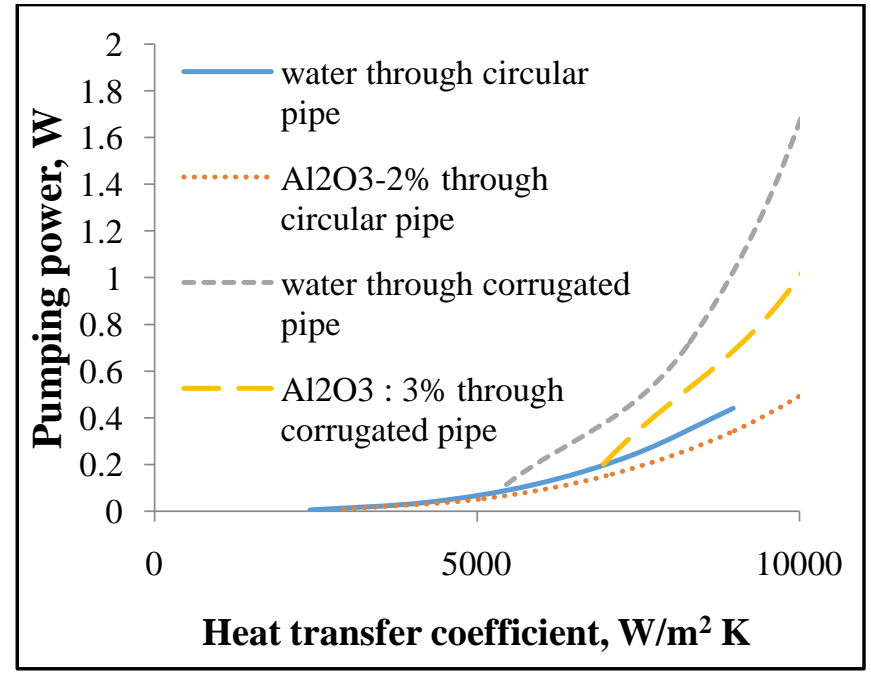

Fig-11: Comparison among the optimum volume fractions of the nanofluid in terms of the enhancement of pumping power.

\section{CONCLUSION}

Corrugated tube and nanofluid both have been used to enhance the heat transfer rate compared to system of water flowing through a simple plain tube. However, this enhancement is achieved at the cost of pumping power required for the flow. This increase in the pumping power is much higher when corrugated tube is used. Addition of nanofluid reduces this pumping power requirement and the minimum occurs at a volume fraction of $3 \%$ in case of corrugated tube. For circular plain tube, at a volume fraction of $5 \%$, the increase in heat transfer rate occurs at the penalty of pumping power which is more than that of water. But in case of corrugated tube, the pumping power requirement for the flow of $5 \% \mathrm{Al}_{2} \mathrm{O}_{3}$-water nanofluid is much lower than that of water.

\section{REFERENCES}

[1] J.A. Eastman, S.U.S. Choi, S. Li,W. Yu, L.J. Thompson, "Anomalously increased effective thermal conductivities of ethylene glycol-based nanofluids containing copper nanoparticles", Appl. Phys. Lett. 78 (2001) 718-720.

[2] S.K. Das, N. Putra, P. Thiesen, W. Roetzel, "Temperature dependence of thermal conductivity enhancement of nanofluids", Journal of Heat Transfer 125 (2003) 567-574.

[3] H. Xie, J. Wang, T. Xi, F. Ai, "Thermal conductivity enhancement of suspensions containing nanosized alumina particles", Int. J. Appl. phys. 91 (2002) 4568-4572.

[4] S. Lee, S.U.S. Choi, S. Li, J.A. Eastman, 1999, "Measuring thermal conductivity of fluids containing oxide nanoparticles", Trans. ASME Journal of Heat Transfer (121) pp. 280-289.

[5] X. Wang, X. Xu, S.U.S. Choi, 1999, "Thermal conductivity of nanoparticle-fluid mixture", J. Thermophys. Heat Transfer (13), pp. 474-480.

[6] Sidi El BecayeMaiga, Cong Tam Nguyen, Nicolas Galanis, Gilles Roy, "Heat transfer behaviours of nanofluids in a uniformly heated tube", Superlattices and Microstructures 35 (2004) 543-557.

[7] SidiEl BecayeMaiga, Samy Joseph Palm, Cong Tam Nguyen, Gilles Roy, Nicolas Galanis, "Heat transfer enhancement by using nanofluids in forced convection flows", International Journal of Heat and Fluid Flow 26 (2005) 530-546.

[8] A. Behzadmehr, M. Saffar-Avval, N. Galanis, "Prediction of turbulent forced convection of a nanofluid in a tube with uniform heat flux using a two phase approach", International Journal of Heat and Fluid Flow 28 (2007) 211-219.

[9] Eiyad Abu-Nada, "Application of nanofluids for heat transfer enhancement of separated flows encountered in a backward facing step", International Journal of Heat and Fluid Flow 29 (2008) 242-249.

[10] V. Bianco, F. Chiacchio, O. Manca, S. Nardini, "Numerical investigation of nanofluids forced convection in circular tubes", Applied Thermal Engineering 29 (2009) 3632-3642.

[11] Devdatta P. Kulkarni, Debendra K. Das, Ravikanth S. Vajjha, "Application of nanofluids in heating buildings and reducing pollution", Applied Energy 86 (2009) 2566-2573.

[12] M. Izadi, A. Behzadmehr, D. Jalali-Vahida, "Numerical study of develop ing laminar forced convection of a nanofluid in an annulus", International Journal of Thermal Sciences 48 (2009) 2119-2129.

[13] Apurba Kumar Santra, SwarnenduSen, Niladri Chakraborty, "Study of heat transfer due to laminar flow of copper-water nanofluid through two isothermally heated parallel plates", International Journal of Thermal Sciences 48 (2009) 391-400.

[14] Weerapun Duangthongsuk, Somchai Wongwises, "Heat transfer enhancement and pressure drop characteristics of $\mathrm{TiO} 2-$ water nanofluid in a doubletube counter flow heat exchanger", International Journal of Heat and Mass Transfer 52 (2009) 20592067.

[15] Yurong He, Yubin Men, Yunhua Zhao, Huilin Lu, Yulong Ding, "Numerical investigation into the convective heat transfer of $\mathrm{TiO} 2$ nanofluids flowing through a straight tube under the laminar flow conditions", Applied Thermal Engineering 29 (2009) 1965-1972.

[16] M. Nasiri, S.Gh. Etemad, R. Bagheri, "Experimental heat transfer of nanofluid through an annular duct", International Communications in Heat and Mass Transfer 38 (2011) 958-963.

[17] Mohamed SakrFadl, "A Numerical Simulation of Heat Transfer Performance Using Different Corrugated Surface Shape", Proceedings of ICFD11: Eleventh International Conference of Fluid Dynamics, December 19-21, 2013, Alexandria, Egypt.

[18] Amador M. Guzman, Maria J. Cardenas, Felipe A. Urzua, Pablo E. Araya, 2009, "Heat transfer enhancement by flow bifurcations in asymmetric wavy wall channels", International Journal of Heat and Mass Transfer (52),pp. 3778-3789. 
[19] E.A.M. Elshafei, M.M. Awad, E. El-Negiry, A.G. Ali, 2010, "Heat transfer and pressure drop in corrugated channels", Energy (35), pp. 101-110.

[20] Abhishek G. Ramgadia, Arun K. Saha, 2012, "Fully developed flow and heat transfer characteristics in a wavy passage: Effect of amplitude of waviness and Reynolds number", International Journal of Heat and Mass Transfer (55), pp. 2494-2509.

[21] Abhishek G. Ramgadia, Arun K. Saha, 2013, "Numerical study of fully developed flow and heat transfer in a wavy passage", International Journal of Thermal Sciences (67), pp. 152-166.

[22] Naphon Paisarn, 2010, "Study on the heat transfer characteristics and pressure drop in channels with arc shaped wavy plates", Journal of Engineering Physics and Thermophysics (83), pp. 62-71.

[23] H. Heidary, M.J. Kermani, "Effect of nano-particles on forced convection in sinusoidal-wall channel", International Communications in Heat and Mass Transfer 37 (2010) 1520-1527.

[24] M.A. Ahmed, N.H. Shuaib, M.Z. Yusoff, A.H. AlFalahi, "Numerical investigations of flow and heat transfer enhancement in a corrugated channel using nanofluid", International Communications in Heat and Mass Transfer 38 (2011) 1368-1375.

[25] M.A. Ahmed, N.H. Shuaib, M.Z. Yusoff, "Numerical investigations on the heat transfer enhancement in a wavy channel using nanofluid", International Journal of Heat and Mass Transfer 55 (2012) 5891-5898.

[26] Hussein, Adnan M., K. V. Sharma, R. A. Bakar, and K. Kadirgama. "The effect of cross sectional area of tube on friction factor and heat transfer nanofluid turbulent flow." International Communications in Heat and Mass Transfer 47 (2013): 49-55.

[27] M.A. Ahmed, M.Z. Yusoff, N.H. Shuaib, "Effects of geometrical parameters on the flow and heat transfer characteristics in trapezoidal-corrugated channel using nanofluid", International Communications in Heat and Mass Transfer 42 (2013) 69-74.

[28] Manavi, Seyed Alborz, Abas Ramiar, and Ali Akbar Ranjbar. "Turbulent forced convection of nanofluid in a wavy channel using two phase model." Heat and Mass Transfer 50, no. 5 (2014): 661-671.

[29] Ashkan vatani, H.A. Muhammad, "Turbulent nanofluid flow over periodic rib-grooved channels", Engineering Applications of Computational Fluid Mechanics, 7 no-3 (2013) 369-381.

[30] B.C. Pak, Y. I. Cho, "Hydrodynamic and heat transfer study of dispersed fluids with submicron metallic oxide particles", Experimental Heat Transfer 11 (1998) 151-155.

[31] Koo, Junemoo, and Clement Kleinstreuer. "A new thermal conductivity model for nanofluids." Journal of Nanoparticle Research 6, no. 6 (2004): 577-588.

[32] Koo, J., and C. Kleinstreuer. "Laminar nanofluid flow in micro heat-sinks." International Journal of Heat and Mass Transfer 48, no. 13 (2005): 2652-2661.

[33] Notter, R.H., and C. A. Sleicher: "A Solution to the Turbulent Graetzs Problem. III. Fully Developed and Entry Heat Transfer Rates," Chem. Eng. Sci., 27 (1972) 2073-2093.

[34] ANSYS Fluent Inc., USA.

\section{BIOGRAPHIES}

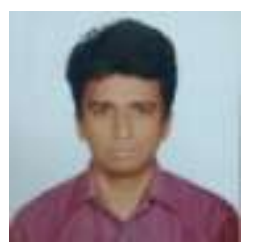

Mohammad Monjurul Ehsan has been serving as an assistant professor at Islamic University of Technology (IUT) since 2010. He has completed his Bachelors of science and Masters of science in Mechanical Engineering in 2010 and 2012 respectively. He has been awarded the most prestigious OIC gold medal for his outstanding academic performance in undergraduate study by the Prime Minister. He has so far published 6 journals, 5 conference papers and 1 book chapter.

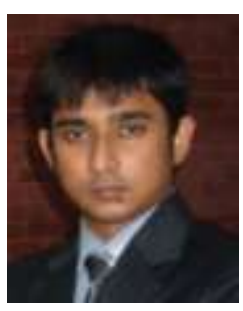

Shafi Noor has been serving as a Lecturer at Islamic University of Technology (IUT) since 2013. He has completed his Bachelors of science and Masters of science in Mechanical Engineering from IUT. He has been awarded the prestigious IUT gold medal for his outstanding academic performance in undergraduate study by the Prime Minister. 